\title{
Testicular ischemia-reperfusion may alter micro-rheological parameters in laboratory
} rats

${ }_{4}$ Norbert Nemeth $^{\mathrm{a}, *}$, Ferenc Kiss $^{\mathrm{a}}$, Zoltan Klarik ${ }^{\mathrm{a}}$, Katalin Peto ${ }^{\mathrm{a}}$, Erzsebet Vanyolos ${ }^{\mathrm{a}}$, ${ }_{5} \quad$ Laszlo Toth $^{\mathrm{b}}$, Istvan Furka ${ }^{\mathrm{a}}$ and Iren Miko ${ }^{\mathrm{a}}$

${ }^{a}$ Department of Operative Techniques and Surgical Research, Institute of Surgery University of Debrecen, Debrecen, Hungary

${ }^{\mathrm{b}}$ Department of Pathology, Medical and Health Science Center, University of Debrecen, Debrecen, Hungary

\begin{abstract}
Ischemia-reperfusion-caused hemorheological alterations have been widely studied but the effect of testicular ischemia-reperfusion has not so far. In this study 14 Sprague-Dawley rats were involved. In the ischemia-reperfusion group under general anaesthesia the left testis was explored by opening the scrotum then the deferent duct and vasculature were clamped for 30 minutes. Testicular microcirculation was monitored by laser Doppler flowmetry. The right testis was untouched. In the control group: only anaesthesia was induced. Blood sampling occurred before and after ischemia, at the 60th minute of reperfusion and on the 1st postoperative day for determining hematological parameters (microcell-counter), erythrocyte deformability (slit-flow ektacytometer) and erythrocyte aggregation (light-transmission aggregometer). After the last blood sampling, testicles were removed for histological examination. Hematological parameter changes reflected inflammatory response. Erythrocyte deformability showed a worsening already at the 60 th minute of reperfusion compared to base and control values. By the 1 st postoperative day further decrease was observed. Erythrocyte aggregation significantly enhanced with great magnitude versus base and control values $(p<0.001)$. However, conventional histological examinations did not show marked testicular injury. The experienced changes can attract attention to the testicular ischemia-reperfusion causing significant effects on hemorheological parameters, which can lead to further harmful microcirculatory consequences.

Keywords: Testicular ischemia-reperfusion, red blood cell aggregation, red blood cell deformability, microcirculation, rat
\end{abstract}

\section{Introduction}

Acute testicular ischemia is still nowadays an important issue in the clinical practice, which is most frequently due to torsion (mainly intra-, extravaginal or mesorchial types) $[8,9,31]$. Besides the severe pain, the occurring ischemia has influence on the spermatogenesis and furthermore, the injury of the blood testis barrier can provoke immune processes leading to contralateral injury [13, 17, 23, 33, 35]. Concerning the microcirculatory alterations there are numerous literature data with various length of ischemia-reperfusion $[9,16,17,28,32]$. In this approach, the hemorheological approach is inseparable, since it is well known, that blood and plasma viscosity, hematocrit, red blood cell deformability as well as red blood cell aggregation are major determinants of the microcirculatory flow [e.g. 2-4, 24, 26, 30].

${ }^{*}$ Corresponding author: Norbert Nemeth, M.D., Ph.D., Department of Operative Techniques and Surgical Research, Medical and Health Science Centre, University of Debrecen, H-4032 Debrecen, Nagyerdei krt. 98., Hungary. Tel./Fax: +36 52 416 915; E-mail: nemeth@med.unideb.hu. 
During tissue or organ ischemia-reperfusion these hemorheological parameters may show changes in different manners, mainly due to free-radical-caused damages, inflammatory processes and metabolic changes as well as acid-base alterations $[3,10,14,18,20]$. Surprisingly, by our knowledge, in the literature there is a lack of conclusive data about the hemorheological changes caused by testicular ischemia-reperfusion.

In present study our aim was to investigate the hypotheses whether 30 minutes of testicular ischemia and the following reperfusion may have deteriorating effect on the testicular microcirculation and on the micro-rheological parameters, such as red blood cell deformability and aggregation in the rat.

\section{Materials and methods}

\subsection{Experimental animals and study design}

The experiments were approved and registered by the University of Debrecen Committee of Animal Research (registration Nr.: 17/2008. UD CAR), in accordance with the Hungarian Animal Protection Act (Law XVIII/1998).

Fourteen adult (7-8 months old) male Sprague-Dawley rats (Janvier Co., France) (bodyweight: $563 \pm 94.3 \mathrm{~g}$ ) were involved into the study. The animals were randomly divided into two equal experimental groups, as Ischemia-Reperfusion (I/R) and Control groups.

\subsection{Operative techniques and blood sampling protocol}

In the I/R group $(n=7)$ under general anesthesia (Thiopenthal ${ }^{\circledR} 60 \mathrm{mg} / \mathrm{kg}$, i.p.) the scrotum was gently shaved, disinfected with Betadine ${ }^{\circledR}$ and isolated. The scrotum was opened by a $2-\mathrm{cm}$ incision over the left testis, which was gently ante-positioned and taken on a wet (using body temperature physiological saline solution) sterile textile. Its deferent duct together with the vessels was atraumatically clamped for 30 minutes in order to induce unilateral ischemia, while the right testicle was kept intact. After the ischemia and completing the microcirculatory tests (see below), the left testis was repositioned, the field was washed with Betadine ${ }^{\circledR}$ and the scrotum was closed in two layers taking simple interrupted stitches and using 3/0 Dexon ${ }^{\circledR}$. In the Control group $(n=7)$ anesthesia was induced but no operation was performed. As analgesia, both experimental groups received Flunixin ${ }^{\circledR}(2.5 \mathrm{mg} / \mathrm{kg}$, s.c. $)$.

For laboratory tests $0.2-0.3 \mathrm{ml}$ blood was obtained via puncturing the lateral tail vein using $26 \mathrm{G}$ needle (anticoagulant: $1.5 \mathrm{mg} / \mathrm{ml} \mathrm{K}_{3}$-EDTA) prior to the ischemia (Base), just after the ischemia (I-30), as well at the 60th minutes of reperfusion (R-60), and also on the 1st postoperative day. After the last blood sampling under general anesthesia, bilateral orchidectomy was performed in both groups for histological examinations. At the end of the experiment protocol, the animals were euthanized.

\subsection{Microcirculatory investigation}

For monitoring the microcirculation of the testicles a LD-01 laser Doppler tissue flowmetry monitoring system (Experimetria Ltd., Hungary) was used with a standard pencil probe (MNP100XP, Oxford Optronix Ltd., UK). The device determines blood flux units (BFU), which were registered for $20 \mathrm{sec}$ after stabilization of the signal. Since evaluation of results from a single-channel laser Doppler device can be 
done by several way, such as using the measured BFU values, arbitrary units, or evaluating the changes (relative values), as well as analyzing the response to a vasoactive agent or ischemic maneuver $[1,19$, 22], we have chosen the evaluation of the average BFU values of a standard time period. The data were analyzed offline, using the average BFU values of each 2-second periods (excluding the highest and the lowest values) of the recorded 20-second testing time.

The BFU together with the temperature (SEN-06-RTH1 stick temperature probe, Experimetria Ltd., Hungary) of the left testicle was measured prior to ischemia (Base) and at the end of the ischemia (I-30). On the 1st postoperative day before orchidectomy measurements were also completed on both testes.

\subsection{Laboratory investigations}

Quantitative and qualitative hematological parameters were determined by a Sysmex F-800 microcell counter (TOA Medical Electronics Co., Ltd., Japan). The tests require approximately $70 \mu \mathrm{l}$ of blood.

Red blood cell deformability was determined using a Rheoscan-D200 slit-flow ektacytometer (Sewon Meditech Inc., South-Korea). In the device vacuum-generated shear stress (SS; 0.5-20 Pa) is used for elongating red blood cells flowing through a $200-220 \mu \mathrm{m}$ high, $40 \mathrm{~mm}$ long slit chamber, while a laser beam is focused on this slit-flow zone. The measurement is based on the analysis of the diffracted laser images pattern from the elongated red blood cells, determining elongation index (EI) values in the function of shear stress (SS [Pa]). EI increases parallelly with the deformability of the cell $[4,12]$. During sample preparation $6 \mu \mathrm{l}$ of blood sample was placed into $600 \mu \mathrm{l}$ high-viscosity isotonic polyvinyl-pyrrolidone solution (PVP, $360 \mathrm{kDa}$; viscosity $=20 \mathrm{mPa} . \mathrm{s}$ ).

For the comparison of EI-SS curves EI values at 1,2,3, 5 and $10 \mathrm{~Pa}$, as well as calculated maximal elongation index $\left(\mathrm{EI}_{\max }\right)$ and the shear stress at half $\mathrm{EI}_{\max }\left(\mathrm{SS}_{1 / 2}[\mathrm{~Pa}]\right)$ were used, according to the Lineaweaver-Burke analysis [5]: $1 / \mathrm{EI}=\mathrm{SS}_{1 / 2} / \mathrm{EI}_{\max } \times 1 / \mathrm{SS}+1 / \mathrm{EI}_{\max }$.

For testing red blood cell aggregation a Myrenne MA-1 erythrocyte aggregometer (Myrenne GmbH, Germany) was used. The measurements require approximately $20 \mu \mathrm{l}$ of blood. During measurements the sample is disaggregated at shear rate of $600 \mathrm{~s}^{-1}$ for a few seconds then suddenly the shear rate drops to zero ( $\mathrm{M}$ mode) or to $3 \mathrm{~s}^{-1}$ shear rate (M1 mode). Then the instruments calculates the aggregation index value by the changes of light-transmission of the sample at the 5th or 10th second of the aggregation process. The indices increase with enhanced red blood cell aggregation [4, 6, 12].

\subsection{Histological examinations}

For histological examinations slides were cut in sagittal plane from the testicle specimens, then stained with hematoxylin-eosin (H\&E).

\subsection{Statistical analysis}

Data are presented as mean \pm standard deviation (S.D.). According to the normality of data distribution, Student $t$-test or Mann-Whitney RS test were used for inter-group comparison, and one-way ANOVA tests (Dunn's or Bonferroni's method) for intra-group comparison.

A $p$ value less than 0.05 was considered as statistically significant. 
3. Results

\subsection{Microcirculatory investigations}

The microcirculatory blood flux units significantly declined during the ischemia (BFU: $13.78 \pm 2.6$;

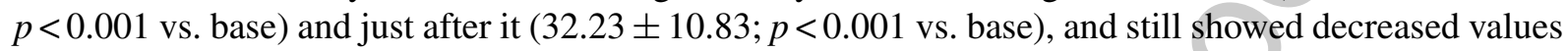
on the 1 st postoperative day $(26.78 \pm 5.47)$ compared to the base $(42.5 \pm 7.1 ; p<0.001)$ or versus the intact right testis' values $(43.45 \pm 8.39 ; p<0.001)$. The microcirculation of the intact side did not show changes compared to the base (Fig. 1).

Compared to the base values $\left(27.27 \pm 1.46^{\circ} \mathrm{C}\right)$, the temperature of the ischemic testis slightly decreased $\left(26.38 \pm 2.84{ }^{\circ} \mathrm{C}\right)$. By the 1 st postoperative day, the temperature of the injured testis was significantly higher $\left(31.08 \pm 1.22^{\circ} \mathrm{C}\right)$ versus the base $(p=0.002)$ or the contralateral, intact testis values $(p=0.039)$. However, the intact testis' temperature $\left(29.46 \pm 0.81^{\circ} \mathrm{C}\right)$ was also significantly higher compared to the base ( $p=0.02)$ (Fig. 2).

\subsection{Hematological parameters}

Table 1 summarizes the results of hematological tests. White blood cell count of the I/R group showed significant elevation by the 1 st postoperative day compared to the Control group (for all: $p=0.001$ ). A rise was seen in monocyte-granulocyte ratio showing significant difference compared to its base: just after ischemia $(p=0.018)$, by the 60th minute of reperfusion $(p<0.001)$ and on the 1 st postoperative day $(p<0.001)$.

The platelet count also elevated in the I/R group, showing significant difference on the 1 st postoperative day compared to the base values $(p=0.002)$ or to the Control group $(p<0.001)$.

The other, erythrocyte-related hematological parameters, such as red blood cell count and hematocrit, suggested only a slight hemoconcentration in the I/R group by the 1 st postoperative day.

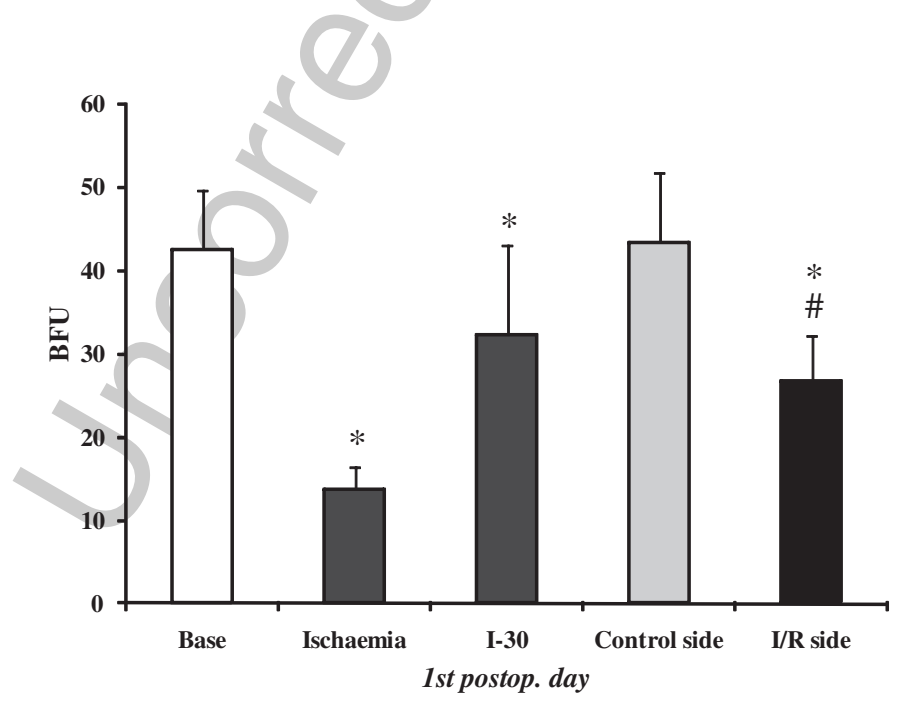

Fig. 1. Blood flow unit (BFU) measured by laser Doppler tissue flowmetry. Base values and changes during/after ischemia, and on the 1 st postoperative day on ipsi- and contralateral testes. ${ }^{*} p<0.05$ vs. Base; \# vs. Control. 


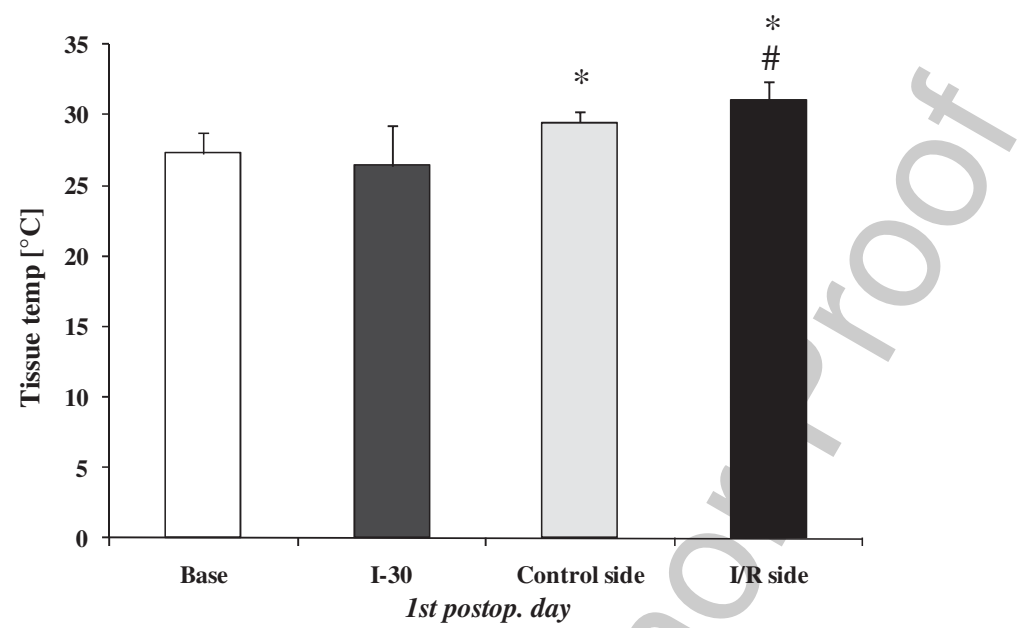

Fig. 2. Tissue temperature $\left[{ }^{\circ} \mathrm{C}\right]$ base values and changes during/after ischemia, and on the 1 st postoperative day on ipsi- and contralateral testes. ${ }^{*} p<0.05$ vs. Base; \# vs. Control.

Table 1

Changes of selected hematological parameters

\begin{tabular}{lrccc}
\hline Variable & \multicolumn{1}{c}{ Base } & I-30 & R-60 & 1st p.o. day \\
\hline WBC $\left[\times 10^{3} / \mu \mathrm{l}\right]$ & $10.69 \pm 1.06$ & $7.66 \pm 0.96$ & $9.68 \pm 2.02$ & $11.37 \pm 4.81^{\#}$ \\
& $7.79 \pm 0.95$ & & & $5.98 \pm 1.05$ \\
$\mathrm{Mo}+\mathrm{Gr} \%[\%]$ & $27.94 \pm 9.81$ & $36.91 \pm 12.35^{*}$ & $58.07 \pm 12.58^{*,+}$ & $61.87 \pm 12.68^{*, \#}$ \\
& $17.25 \pm 5.24$ & & & $27.1 \pm 7.04$ \\
$\mathrm{RBC}\left[\times 10^{6} / \mu \mathrm{l}\right]$ & $6.9 \pm 1.25$ & $7.2 \pm 0.69$ & $7.42 \pm 0.38$ & $7.64 \pm 0.8$ \\
& $7.58 \pm 0.9$ & & & $7.54 \pm 1.23$ \\
Hct $[\%]$ & $38.38 \pm 7.24$ & $40.4 \pm 4.49$ & $41.21 \pm 2.03$ & $41.67 \pm 4.77$ \\
& $43.02 \pm 5.74$ & & & $42.76 \pm 6.19$ \\
$\mathrm{MCV}[\mathrm{fl}]$ & $55.57 \pm 0.94$ & $56.03 \pm 1.87$ & $55.5 \pm 1.01$ & $54.47 \pm 0.98$ \\
& $56.68 \pm 3.17$ & & & $56.84 \pm 2.26$ \\
$\mathrm{MCH}[\mathrm{pg}]$ & $15.65 \pm 0.41$ & $15.83 \pm 0.51$ & $15.61 \pm 0.43$ & $15.12 \pm 1.24$ \\
& $15.57 \pm 0.75$ & & & $15.86 \pm 0.6$ \\
$\mathrm{Plt}\left[\times 10^{3} / \mu \mathrm{ll}\right]$ & $716.7 \pm 181.4$ & $745 \pm 140.4$ & $731.7 \pm 158.5$ & $913.1 \pm 99.3^{*, \#}$ \\
& $784.4 \pm 132.7$ & & & $707.9 \pm 140.4$ \\
\hline
\end{tabular}

means \pm S.D.; Control values in italics. Base $=$ before ischemia; $\mathrm{I}-30=$ the end of the 30 -minute ischemia; $\mathrm{R}-60=$ the 60 th minute of the reperfusion; 1 st p.o. day $=1$ st postoperative day; ${ }^{*} p<0.05$ vs. Base; ${ }^{\#}$ vs. Control; ${ }^{+}$vs. I-30.

\subsection{Red blood cell deformability}

Figure 3 shows the elongation index (EI) values in the function of shear stress (SS [Pa]). On the EISS curve plots only a slight decrease was visible in the I/R group (Fig. 3A) compared to the Control (Fig. 3B). 

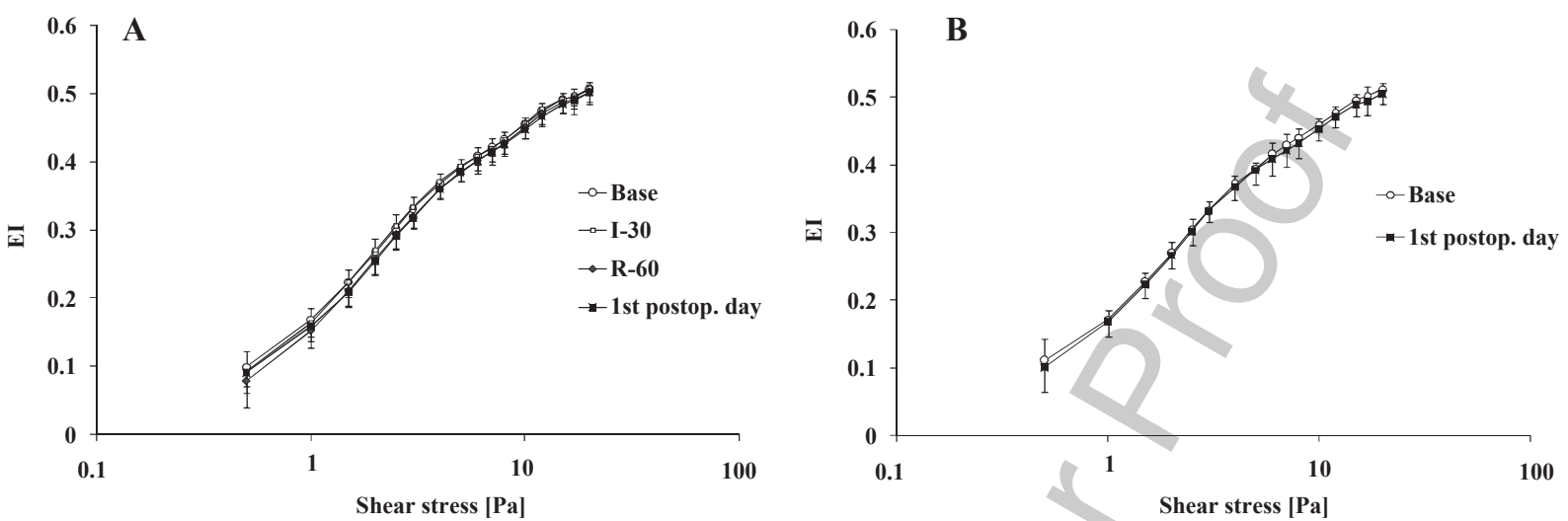

Fig. 3. Elongation index (EI) - shear stress (SS [Pa]) curves of Ischemia-Reperfusion (A) and Control (B) groups before ischemia (base), at the end of the ischemic period (I-30), at the 60th minute of reperfusion (R-60) and on the 1st postoperative day.

Table 2

Comparative data of elongation index (EI) - shear stress (SS [Pa]) curves

\begin{tabular}{lcccc}
\hline Variable & Base & $\mathrm{I}-30$ & $\mathrm{R}-60$ & 1st p.o. day \\
\hline EI at $1 \mathrm{~Pa}$ & $0.168 \pm 0.016$ & $0.162 \pm 0.025$ & $0.151 \pm 0.024^{*}$ & $0.158 \pm 0.014$ \\
& $0.171 \pm 0.013$ & & & $0.168 \pm 0.022$ \\
EI at $2 \mathrm{~Pa}$ & $0.267 \pm 0.019$ & $0.269 \pm 0.019$ & $0.256 \pm 0.023$ & $0.254 \pm 0.019$ \\
& $0.269 \pm 0.015$ & & & $0.266 \pm 0.02$ \\
EI at $3 \mathrm{~Pa}$ & $0.331 \pm 0.017$ & $0.333 \pm 0.016$ & $0.318 \pm 0.017^{*}$ & $0.317 \pm 0.014^{\#}$ \\
& $0.331 \pm 0.014$ & & & $0.331 \pm 0.017$ \\
EI at $5 \mathrm{~Pa}$ & $0.391 \pm 0.012$ & $0.392 \pm 0.009$ & $0.384 \pm 0.013$ & $0.385 \pm 0.014$ \\
& $0.393 \pm 0.009$ & & & $0.391 \pm 0.021$ \\
EI at $10 \mathrm{~Pa}$ & $0.454 \pm 0.010$ & $0.455 \pm 0.007$ & $0.450 \pm 0.015$ & $0.446 \pm 0.013$ \\
& $0.459 \pm 0.009$ & & & $0.452 \pm 0.017$ \\
EI $_{\max }$ & $0.574 \pm 0.022$ & $0.570 \pm 0.019$ & $0.575 \pm 0.027$ & $0.576 \pm 0.022$ \\
& $0.572 \pm 0.011$ & & & $0.572 \pm 0.013$ \\
$\mathrm{SS}_{1 / 2}[\mathrm{~Pa}]$ & $2.42 \pm 0.43$ & $2.71 \pm 1.11$ & $2.84 \pm 0.74 !$ & $2.63 \pm 0.36$ \\
& $2.39 \pm 0.25$ & & & $2.45 \pm 0.53$ \\
\hline
\end{tabular}

means \pm S.D.; Control values in italics. Base $=$ before ischemia; $\mathrm{I}-30=$ the end of the 30 -minute ischemia; $\mathrm{R}-60=$ the 60 th minute of the reperfusion; 1 st p.o. day $=1$ st postoperative day $* p<0.05 \mathrm{vs}$. Base; ${ }^{*} \mathrm{vs}$. Control; ! $p=0.051$ vs. Base.

Table 2 shows comparative data of the EI-SS curves. Compared to the base, significantly lower EI values were measured in the I/R group at the 60th minute of reperfusion: at $1 \mathrm{~Pa}(p=0.028)$ and at $3 \mathrm{~Pa}$ $(p=0.048)$. On the 1 st postoperative day the I/R group showed significantly lower EI values compared to the Control group $(p=0.037)$. The calculated $\mathrm{EI}_{\max }$ values showed a slight decrease by the end of the ischemia, while by the 60th minute of the reperfusion, moderate increase of the $\mathrm{SS}_{1 / 2}$ values almost reached the significant level ( $p=0.051)$ versus the base (Table 2$)$. These non-uniform differences could be originated from the shape-alterations of the individual EI-SS curves. 

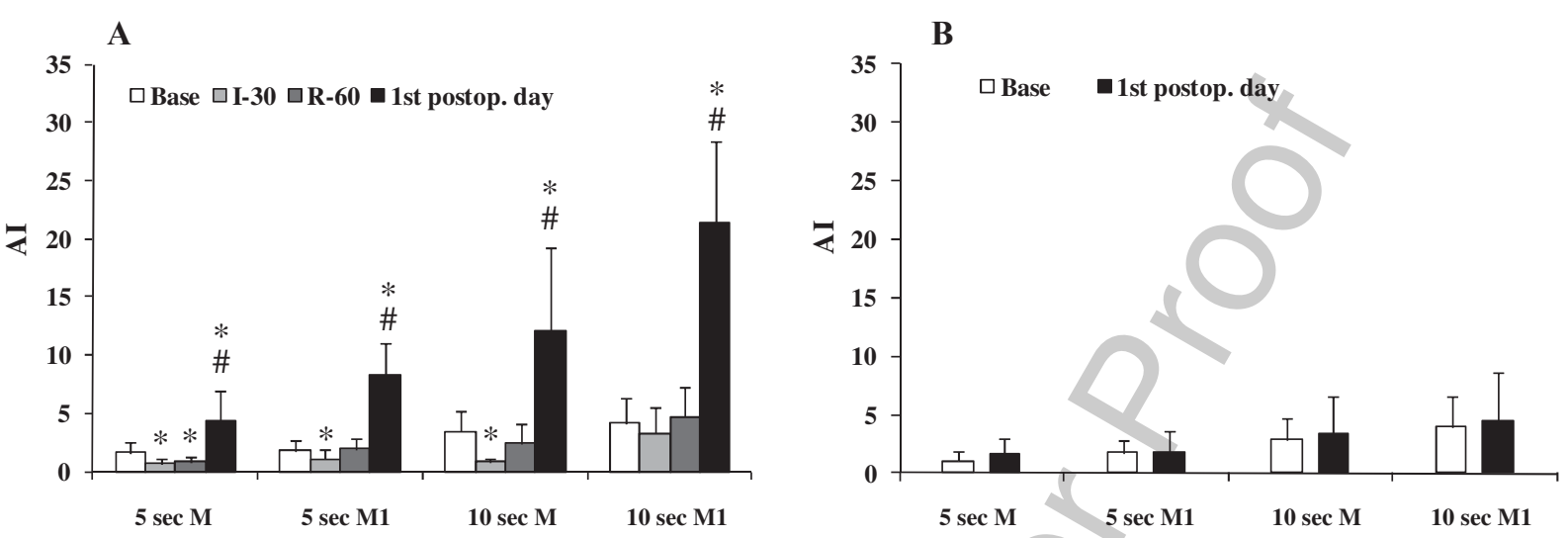

Fig. 4. Red blood cell aggregation index values (M. M1 5 and $10 \mathrm{sec}$ ) of Ischemia-Reperfusion (A) and Control (B) groups before ischemia (base), at the end of the ischemic period (I-30), at the 60th minute of reperfusion (R-60) and on the 1st postoperative day. $* p<0.05$ vs. Base; \# vs. Control.

\subsection{Red blood cell aggregation}

The red blood cell aggregation index values showed significant difference in the I/R group already by the end of 30-minute ischemia (Fig. 4A). Interestingly, this alteration was an initial decrease ( $5 \mathrm{sec} \mathrm{M}$ index: $p=0.003 ; 5 \mathrm{sec}$ M1: $p=0.004 ; 10 \mathrm{sec} \mathrm{M}: p<0.001$ vs. base).

By the 60th minute of reperfusion the aggregation index values started to increase, reaching the base values (only $5 \mathrm{sec} \mathrm{M}$ values differed significantly compared to base: $p=0.018$ ). By the 1 st postoperative day, the rise in all aggregation index values of the I/R group was observed $(5 \mathrm{sec} \mathrm{M}: 4.29 \pm 2.65, p<0.01$ vs. base and $p=0.001$ vs. Control; $5 \mathrm{sec}$ M1:8.27 $\pm 2.69, p<0.001$ vs. base and Control; $10 \mathrm{sec}$ M: $12.09 \pm 7.14, p<0.001$ vs. base and Control; 10 sec M1 : $21.41 \pm 6.88, p<0.001$ vs. base and Control). In the Control group we did not find any important changes (Fig. 4B).

\subsection{Histological results}

Using H\&E staining and conventional light-microscopy, in the I/R group only mild inflammatory induration was seen mostly in the surrounding soft tissues of the testicles and in the epididymis.

\section{Discussion}

For the experimental investigation of testicular ischemia several models are known on laboratory animal species (mouse, rat, hamster, rabbit and porcine) [9, 16, 17, 23, 27, 28, 31, 32]. Most of the studies include microcirculatory, hemodynamic and histological investigation.

The occurring tissue injury during ischemia can also involve and affect the integrity of the blood testis barrier, which can induce such inflammatory and immunological processes that can cause further injuries both in ipsi- and contralateral testicles [10, 17, 21, 23, 33, 34].

When evaluating the results, it may be interesting to consider the testicular volume, and its ratio to the whole body, too. In rats the testicles are almost fully developed at the age of 70 days, however, the volume is still increasing: beyond the age of 3 months it is typically $1600 \mathrm{~mm}^{3}$ or above in Wistar rats 
$[11,29]$. Further questions may arise depending on the laboratory animal species used for the testicular torsion model the critical ischemic time in the preservation of the spermatogenetic function alters, so the testis sensitivity against ischemic time may show species-related differences. Based on literature data in rats 60-minute ischemia is the critical time for salvaging the testes' full biological role [31], while in mice it is 120 minutes [17].

From the hemorheological aspects little is known in the literature about spermatic cord torsion. It is accepted that the majority of the injuries in the testis could be caused by the ischemia-reperfusion generated oxygen free-radicals and activated neutrophils [10, 17, 25]. The hemorheological factors, especially the micro-rheological parameters of the red blood cells, are sensitive to ischemia-reperfusion injuries $[3,14,20]$. Due to the impairment of these factors the microcirculation may further be disturbed $[2,3,24,30]$.

Numerous literature data on blood flow and microcirculatory changes can be comparable to our findings. Lievano et al. found that after testicular torsion (ischemia) the blood flow was elevated not only in the ipsilateral but also in the contralateral testicle in a porcine model. Blood flow values were measured by radiolabeled microsphere technique [16]. Tanyel et al. found similar results in a rabbit model using electromagnetic flowmeter [28]. Nguyen et al. investigated the effect of testicular torsion in porcine using radiolabeled microsphere technique: they found that (after normalizing the data to body weight) the blood flow of the contralateral testicle was reduced during the time of the torsion, then 1 hour after detorsion it became to elevate [21]. Furthermore, Turner et al. investigated the microcirculation using laser Doppler flowmetry in Sprague-Dawley rats and their results were also similar: during torsion values were consumedly decreased and in the early phase of reperfusion could be partly normalized [32].

In the background or because of the microcirculatory changes, alterations could be found also in the rheological parameters of red blood cells. Due to ischemia, the rheology of blood in the excluded vascular region is changing, depending on the length of ischemia, the temperature and on the anatomical properties of the excluded region $[2,3,14,20]$.

In systemic venous blood, red blood cell deformability decreased by the 1 st hour of reperfusion then still worsened by the 1st postoperative day but of a smaller magnitude. Interestingly, the shape of the EI-SS curves were not equal, because some differences were found to be significant at 1 and $3 \mathrm{~Pa}$, but not at other investigated shear stress values. However, EI values were decreased. Thus, we cannot state that 30-min testicular ischemia and the following reperfusion with the inflammatory response reactions caused an obvious decrease in red blood cell deformability. In parallel with this, red blood cell aggregation parameters showed a great elevation by the 1 st postoperative day compared to Control and base values. In case of rats the erythrocyte aggregation values are typically lower and very low; therefore the postoperative elevation of the aggregation index values can be considered impressive [36].

The elevated aggregation index refers to enhanced red blood cell aggregation, of which in vivo consequences are diversified [2, 24, 30]. In the background of red blood cell aggregation changes several factors might be determinant, such as change of the fibrinogen concentration, alterations of the glycocalyx, lactate concentration and $\mathrm{pH}$ level changes [3, 20]. Ischemia-reperfusion and tissue damage-induced inflammation are known to cause micro-rheological alterations $[3,14,18,20,30]$. On the 1st postoperative day following the 30-minute ischemia there was no notable histological change in the testicular parenchyma but in the epididymis and in the surrounding tissue the signs of inflammation were detectable. However, compared to our previous experiments such a great elevation in aggregation index values was very high. It may reflect acute phase reaction $[3,14]$ as we also observed in other ischemia-reperfusion models [18-20]. Its magnitude may suggest even sepsis [3], but white blood cell count changed in a relatively small manner. However, the monocyte-granulocyte ratio doubled by the 1 st postoperative day. 
During the sampling on the 1st postoperative day, we did not see obvious macroscopical signs for the presence of sepsis.

Red blood cell aggregation can be measured or estimated by several methods $[4,6,12]$, including the light-transmission technique that was used in this study. As it was concluded by Baskurt et al. in 2009 , the comparability of various commercially available methods are generally satisfactory, but the instrumental limitations existing, mostly when red blood cell aggregation or deformability are changed in great manner [7]. Using the Myrenne aggregometer the measured values reflect the aggregation process at different time points (5 or $10 \mathrm{sec}$ ) and under stasis (M values) or at a low, $3 \mathrm{~s}^{-1}$ shear rate (M1 values) $[6,12,15]$. Although they describe the same process, they are different values, thus we analyzed them as individual parameters. According to our experiences, both 5 and $10 \mathrm{sec}$ modes are useful, since in animal blood we often saw zero values sporadically in M, M1 values both in 5 and 10 modes. It is also known that hematocrit affect the aggregation index values. The hematocrit data ranged between $\sim 38-43 \%$. It is a relative narrow range, and it would have been impossible to adjust the hematocrit to a constant value (e.g., for $40 \%$ ) in these small amount of blood samples.

It would be favorable if that kind of methods were available, which could in vivo and objectively analyze the microcirculatory parameters, the changes of the rheological, altogether with the micro-rheological properties.

\section{Conclusions}

These findings on the changes of micro-rheological parameters of systemic venous blood samples can attract attention to significant hemorheological effects of testicular ischemia-reperfusion in this rat model, which may related to microcirculatory alterations. The largest changes were seen in the red blood cell aggregation parameters, proving the importance and sensitivity of this measurement. Exploring the dynamics of these postoperative changes requires further studies, even with comparative analyses of therapeutic possibilities.

\section{Acknowledgments}

Authors are grateful to the technical and laboratory staff of the Department of Operative Techniques and Surgical Research at University of Debrecen. Grants: OTKA F-68323 and OTKA K-67779; Janos Bolyai Research Scholarship of the Hungarian Academy of Sciences (N. Nemeth); and supported by UD Faculty of Medicine Research Fund (Bridging Fund 2012).

The authors comply with the Ethical Guidelines for Publication in Clinical Hemorheology and Microcirculation as published on the IOS Press website and in Volume 44, 2010, pp. 1-2 of this journal.

\section{References}

[1] B.A. Al-Tahami, Y.T. Bee, A.A. Ismail and A.H. Rasool, Impaired microvascular endothelial function in relatively young obese humans is associated with altered metabolic and inflammatory markers, Clin Hemorheol Microcirc 47 (2011), 87-97.

[2] O.K. Baskurt, In vivo correlates of altered blood rheology, Biorheology 45 (2008), 629-638.

[3] O.K. Baskurt, Mechanisms of blood rheology alterations, in: Handbook of Hemorheology and Hemodynamics, O.K. Baskurt, M.R. Hardeman, M.W. Rampling and H.J. Meiselman, eds., IOS Press, Amsterdam, The Netherlands, 2007, pp. 170-190. 
[4] O.K. Baskurt, M. Boynard, G.C. Cokelet, P. Connes, B.M. Cooke, S. Forconi, M.R. Hardeman, F. Jung, F. Liao, H.J. Meiselman, G. Nash, N. Nemeth, B. Neu, B. Sandhagen, S. Shin, G. Thurston and J.L. Wautier, International, expert panel for standardization of hemorheological methods, new guidelines for hemorheological laboratory techniques, Clin Hemorheol Microcirc 42 (2009), 75-97.

[5] O.K. Baskurt, M.R. Hardeman, M. Uyuklu, P. Ulker, M. Cengiz, N. Nemeth, S. Shin, T. Alexy and H.J. Meiselman, Parameterization of red blood cell elongation index - shear stress curves obtained by ektacytometry, Scand J Clin Lab Invest 69 (2009), 777-788.

[6] O. Baskurt, B. Neu and H.J. Meiselman, Measurement of red blood cell aggregation, in: Red blood cell aggregation, O. Baskurt, B. Neu and H.J. Meiselman, eds., CRC Press, Boca Raton, London, New York, USA, 2012, pp. 63-132.

[7] O.K. Baskurt, M. Uyuklu, P. Ulker, M. Cengiz, N. Nemeth, T. Alexy, S. Shin, M.R. Hardeman and H.J. Meiselman, Comparison of three instruments for measuring red blood cell aggregation, Clin Hemorheol Microcirc 43 (2009), $283-298$.

[8] D.D. Cokkinos, E. Antypa, P. Tserotas, E. Kratimenou, E. Kyratzi, I. Deligiannis, G. Kachrimanis and P.N. Piperopoulos, Emergency ultrasound of the scrotum: A review of the commonest pathologic conditions, Curr Probl Diagn Radiol 40 (2011), 1-14.

[9] R.T. Ellati, P.K. Kavoussi, T.T. Turner and J.J. Lysiak, Twist, shout: A clinical and experimental review of testicular torsion, Korean J Urol 50 (2009), 1159-1167.

[10] D.W. Filho, M.A. Torres, A.L. Bordin, T.B. Crezcynski-Pasa and A. Boveris, Spermatic cord torsion, reactive oxygen and nitrogen species and ischemia-reperfusion injury, Mol Aspects Med 25 (2004), 199-210.

[11] F. Gaytan, M.C. Lucena, E. Munoz and R. Paniagua, Morphometric aspects of rat testis development, J Anat 145 (1986), $155-159$.

[12] M.R. Hardeman, P.T. Goedhart and S. Shin, Methods in hemorheology, in: Handbook of Hemorheology and Hemodynamics, O.K. Baskurt, M.R. Hardeman, M.W. Rampling and H.J. Meiselman, eds., IOS Press, Amsterdam, The Netherlands, 2007, pp. 242-266.

[13] T. Jozsa, A. Telek, B. Kutasy, M. Benyo, G. Csanadi, I. Kovacs, Gy. Balla, T. Flasko, L. Csernoch and Cs. Kiss, Effect of hydrocele on appendix testis in children, Asian J Androl 11 (2009), 741-745.

[14] E. Kayar, F. Mat, H.J. Meiselman and O.K. Baskurt, Red blood cell rheological alterations in a rat model of ischemiareperfusion injury, Biorheology 38 (2001), 405-414.

[15] B.K. Lee, T. Alexy, R.B. Wenby and H.J. Meiselman, Red blood cell aggregation quantitated via Myrenne aggregometer and yield shear stress, Biorheology 44 (2007), 29-35.

[16] G. Lievano, L. Nguyen, J. Radhakrishnan, L. Fornell and E. John, New animal model to evaluate testicular blood flow during testicular torsion, J Pediatr Surg 34 (1999), 1004-1006.

[17] J.J. Lysiak, S.D. Turner, Q.A. Nguyen, K. Singbartl, K. Ley and T.T. Turner, Essential role of neutrophils in germ cell-specific apoptosis following ischemia/reperfusion injury of the mouse testis, Biol Reprod $\mathbf{6 5}$ (2001), 718-725.

[18] N. Nemeth, F. Kiss, T. Hever, E. Brath, E. Sajtos, I. Furka and I. Miko, Hemorheological consequences of hind limb ischemia-reperfusion differ in normal and gonadectomised male and female rats, Clin Hemorheol Microcirc 50 (2012), 197-2011.

[19] N. Nemeth, T. Lesznyak, E. Brath, G. Acs, A. Nagy, J. Pap Szekeres, I. Furka and I. Miko, Changes in microcirculation after ischemic process in rat skeletal muscle, Microsurgery 23 (2003), 419-423.

[20] N. Nemeth, I. Miko, A. Furka, F. Kiss, I. Furka, A. Koller and M. Szilasi, Concerning the importance of changes in hemorheological parameters caused by acid-base and blood gas alterations in experimental surgical models, Clin Hemorheol Microcirc 51 (2012), 43-50.

[21] L. Nguyen, G. Lievano, L. Ghosh, J. Radhakrishnan, L. Fornell and E. John, Effect of unilateral testicular torsion on blood flow and histology of contralateral testes, J Pediatr Surg 34 (1999), 680-683.

[22] A.N. Obeid, N.J. Barnett, G. Dougherty and G. Ward, A critical review of laser Doppler flowmetry, J Med Eng Technol 14 (1990), 178-181.

[23] A. Pampal, I.O. Ozen, G. Ekingen, B. Demirogullari, F. Helvacioglu and G. Take, The morphological evaluation of ipsilateral and contralateral vasa deferentia in a rat model of unilateral spermatic cord torsion, Pediatr Surg Int $\mathbf{2 6}$ (2010), 287-292.

[24] A.S. Popel and P.C. Johnson, Microcirculation and hemorheology, Ann Rev Fluid Mech 37 (2005), 43-69.

[25] M.G. Rodriguez, C. Rival, M.S. Theas and L. Lustig, Immunohistopathology of the contralateral testis of rats undergoing experimental torsion of the spermatic cord, Asian J Androl 8 (2006), 576-583.

[26] B.Y. Salazar Vazquez, P. Cabrales, A.G. Tsai and M. Intaglietta, Nonlinear cardiovascular regulation consequent to changes in blood viscosity, Clin Hemorheol Microcirc 49 (2011), 29-36. 
[27] C. Savas, H. Dindar, A. Bilgehan, O. Ataoglu and S. Yucesan, Pentoxifylline attenuates reperfusion injury in testicular torsion, Scand J Urol Nephrol 36 (2002), 65-70.

[28] F.C. Tanyel, N. Buyukpamukcu and A. Hicsonmez, Contralateral testicular blood flow during unilateral testicular torsion, Br J Urol 63 (1989), 522-524.

[29] S. Taskinen, M. Taavitsainen and S. Wikstrom, Measurement of testicular volume: Comparison of 3 different methods, $J$ Urol 155 (1996), 930-933.

[30] I.A. Tikhomirova, A.O. Oslyakova and S.G. Mikhailova, Microcirculation and blood rheology in patients with cerebrovascular disorders, Clin Hemorheol Microcirc 49 (2011), 295-305.

[31] T.T. Turner, Acute experimental testicular torsion. No effect on the contralateral testis, $J$ Androl 6 (1985), 65-72.

[32] T.T. Turner, H.J. Bang and J.J. Lysiak, Experimental testicular torsion: Reperfusion blood flow and subsequent testicular venous plasma testosterone concentrations, Urology 65 (2005), 390-394.

[33] T.T. Turner and K.J. Brown, Spermatic cord torsion: Loss of spermatogenesis despite return of blood flow, Biol Reprod 49 (1993), 401-407.

[34] T.T. Turner, K.S.K. Tung, H. Tomomasa and L.W. Wilson, Acute testicular ischemia results in germ cell-specific apoptosis in the rat, Biol Reprod 57 (1997), 1267-1274.

[35] R.M. Vigueras, G. Reyes, J. Rojas-Castaneda, P. Rojas and R. Hernandez, Testicular torsion and its effects on the spermatogenic cycle in the contralateral testis of the rat, Lab Anim 38 (2004), 313-320.

[36] U. Windberger and O.K. Baskurt, Comparative hemorheology, in: Handbook of Hemorheology and Hemodynamics, O.K. Baskurt, M.R. Hardeman, M.W. Rampling and H.J. Meiselman, eds., IOS Press, Amsterdam, The Netherlands, 2007, pp. 267-285. 